\title{
Manajemen Pengendalian Gulma Tanaman Kelapa Sawit (Elaeis Guineensis Jacq.) di Kebun Aneka Persada, Riau
}

\author{
Weed Control Management of Oil Palm (Elaeis Guineensis Jacq.) at Aneka Persada Estate, Riau
}

\section{Yudha Saputra dan Adolf Pieter Lontoh*}

\author{
Departemen Agronomi dan Hortikultura, Fakultas Pertanian, Institut Pertanian Bogor (Bogor Agricultural \\ University), Jl. Meranti, Kampus IPB Darmaga, Bogor 16680, Indonesia \\ Telp. \& Faks. 0251-8629353 e-mail: agronipb@indo.net.id \\ Penulis untuk korespondensi : alfpiton@yahoo.com
}

Disetujui : 20 Agustus 2018 / Published Online 3 September 2018

\begin{abstract}
Research was held at Aneka Persada Estate, Riau in 6 February until 6 June 2017. The goal of the research is increasing profesional, technical, management and analysis at the field with do the activity based on the company. Observation of primary data was weed domination, weed control method, condition of weed after application herbicide, the use pf personal protective equipment, condition of sprayer and labors. The resulf of observation at six block sample showed that very domination weed is A.intrusa, D.ciliaris, B.alata, M.bracteata, dan C.lapacea. A.intrusa was dead after WAF (week after treatment) with ingredient Isopropilamina glifosat $480 \mathrm{gl}^{-1}+$ Metil metsulfuron $20 \%$ with each does $115 \mathrm{ml} \mathrm{ha} \mathrm{a}^{-1}+4,5 \mathrm{~g} \mathrm{ha}{ }^{-1}$. The result of test was showed that the parameter of flow rate, velocity of walk, and labour output is very different, it means that application with MHS is more effective than knapsack sprayer because target area can be larger.
\end{abstract}

Keywords: : Aneka Persada Estate, condition of weed after application, target area, weed domination

\begin{abstract}
ABSTRAK
Kegiatan penelitian dilaksanakan di Kebun Aneka Persada, Riau mulai 6 Februari 2017 sampai 6 Juni 2017. Penelitian ini bertujuan meningkatkan kemampuan profesional, teknis, manajerial, dan analisis kegiatan di lapangan dengan melaksanakan kegiatan sesuai tahapan yang ada di lokasi penelitian. Pengamatan data primer yang dilakukan yaitu dominansi jenis gulma, metode pengendalian gulma, kondisi gulma dominan setelah semprot, metode pengendalian gulma yang digunakan, alat pelindung diri (APD), kondisi alat penyemprot, dan tenaga kerja. Hasil pengamatan pada 6 blok yang diamati menunjukkan bahwa vegetasi gulma yang dominan yaitu A. intrusa, D. ciliaris, B. alata, M.bracteata, dan C. lapacea. Asystasia intrusa mati setelah $3 \mathrm{MSA}$ dengan herbisida berbahan aktif Isopropilamina glifosat $480 \mathrm{~g} \mathrm{l}^{-1}+$ Metil metsulfuron $20 \%$ dosis masing-masing $115 \mathrm{ml} \mathrm{ha}^{-1}+4,5 \mathrm{~g} \mathrm{ha}^{-1}$. Hasil uji yang dilakukan bahwa parameter flowrate, kecepatan jalan, dan prestasi kerja terdapat perbedaan yang sangat nyata, yang berarti bahwa penggunaan MHS lebih efektif dan efisien daripada penggunaan knapsack sprayer karena luasan semprot yang dapat dicakup menjadi lebih luas.
\end{abstract}

Kata kunci : gulma dominan, kebun Aneka Persada, kondisi gulma dominan setelah semprot, luasan semprot. 


\section{PENDAHULUAN}

Kelapa sawit merupakan salah satu tanaman yang berkontribusi dalam perekonomian negara melalui kegiatan ekspor Indonesia. Pengaruh kelapa sawit dalam membantu nilai ekspor tidak lepas dari produksi yang dihasilkan. Menurut Ditjenbun (2016), Luas areal perkebunan kelapa sawit Indonesia pada tahun 2015 mencapai 11300 370 a dengan produksi sebesar 31284306 ton. Andika dan Widoro (2013) menyatakan, rata-rata produktivitas kebun kelapa sawit Indonesia masih lebih rendah dibandingkan dengan Malaysia. Produktivitas rata-rata TBS Indonesia pada tahun 2013 adalah 16 ton ha $^{-1}$ tahun $^{-1}$ dengan rendemen minyak $24-25 \%$, dan produktivitas CPO yang mampu dihasilkan sebesar 3.7 ton ha $^{-1}$ tahun $^{-1}$.

Usaha untuk meningkatkan produktivitas tanaman dapat dilakukan melalui kegiatan pemeliharaan yang tepat, salah satunya adalah pengendalian gulma. Tanaman perkebunan mudah dipengaruhi oleh gulma, khususnya untuk tanaman muda. Beberapa laporan menginformasikan bahwa pengaruh gulma pada perkebunan kelapa sawit dapat mengurangi produksi panen. Mikania micrantha misalkan, dilaporkan dapat menurunkan produksi Tandan Buah Segar (TBS) sebesar 20\% karena pertumbuhannya sangat cepat dan mengeluarkan zat allelopatik yang bersifat racun bagi tanaman. Menurut Ditjenbun (2013), di Provinsi Jambi tahun 2010 tercatat kerugian hasil pada komoditi kelapa sawit yang disebabkan oleh Mikania micrantha sebesar Rp38 110500.00 dengan luas serangan 757.5 ha, Imperata cylindrica sebesar Rp59 971500.00 dengan luas serangan 1086 ha, Paspalum conjugatum sebesar Rp43 416599.00 dengan luas serangan 1149.9 ha.

Tingkatan dalam melakukan pengelolaan gulma adalah pencegahan, pengendalian, dan pemberantasan. Pencegahan dilakukan dengan cara mencegah pertumbuhan gulma baru pada suatu tempat serta membatasi pertumbuhan gulma di kebun (Ashton and Monaco, 1991). Martins et al. (2015) menambahkan, pentingnya menjaga kualitas tanah merupakan salah satu unsur demi keberlanjutan budidaya. Periode sampling, tanaman penutup tanah (cover crop) yang berbeda, dan metode pengendalian gulma mempengaruhi keberagaman gulma, bobot kering gulma, kandungan karbon tanah dan tingkat humifikasi.

Pengendalian gulma terpadu bermanfaat untuk meminimalisir dampak dari penggunaan herbisida, emisi gas rumah kaca, erosi tanah dan biodiversitas (Chikowo et al., 2009). Menurut
Antralina et al. (2015), dua strategi efektif dalam pengendalian secara kimiawi adalah dengan melakukan rotasi herbisida dan adanya pencampuran penggunaan herbisida. Pencampuran herbisida dengan bahan aktif yang berbeda bertujuan untuk mendapatkan kontrol spektrum yang lebih luas dan diharapkan untuk memperlambat munculnya gulma resisten terhadap herbisida, mengurangi biaya produksi, dan mengurangi residu herbisida.

Tujuan umum kegiatan penelitian ini adalah meningkatkan kemampuan profesional mahasiswa sesuai kompetensinya dalam memahami dan menghayati proses kerja secara nyata, dan meningkatkan kemampuan teknis, manajerial, dan analisis kegiatan di lapangan dengan melaksanakan kegiatan sesuai tahapan yang ada di lokasi penelitian. Kegiatan penelitian ini memiliki tujuan khusus yaitu mengetahui identifikasi jenis dan gulma yang dominan pada kelapa sawit. memahami teknik dan teknis pengendalian gulma yang tepat dan efektif terhadap vegetasi gulma yang ada di lapangan, dan memahami teknik pengendalian gulma pada areal tanaman belum menghasilkan dan tanaman menghasilkan di lapang.

\section{METODE PENELITIAN}

Kegiatan penelitian yang terdiri dari kegiatan utama dan kegiatan khusus. Metode pelaksanaan kegiatan utama yang dilakukan selama kegiatan penelitian yaitu melalui metode langsung dan metode tidak langsung yang menyangkut aspek teknis dan aspek manajerial. Metode langsung adalah praktik kerja langsung di lapangan, dan wawancara dengan asisten dan mandor. Metode tidak langsung yaitu mempelajari RKT (Rencana Kerja Tahunan) dan laporan kerja harian.

Pelaksanaan kegiatan penelitian dibagi dalam tiga tahap yaitu satu bulan sebagai KHL (Karyawan Harian Lepas), satu bulan sebagai pendamping mandor dan dua bulan sebagai pendamping asisten. Pelaksanaan sebagai KHL dilakukan dengan bekerja bersama karyawan lainnya. Kegiatan meliputi pemeliharaan tanaman, pemupukan, pengendalian gulma serta pemanenan, namun kegiatan lebih difokuskan pada pengendalian gulma. Kegiatan penelitian selanjutnya pada bulan kedua adalah sebagai mandor selama satu bulan. Kegiatan yang dilakukan selama menjadi pendamping mandor adalah mengawasi pekerjaan karyawan di lapangan serta membuat laporan kerja harian. Bidang kegiatan pada dua bulan selanjutnya adalah sebagai pendamping asisten divisi. 
Kegiatan yang dilakukan meliputi pengecekan hasil kerja mandor semprot dan panen, mengarahkan dan mengawasi kerja para mandor maupun karyawan, serta melakukan administrasi di kantor divisi.

Pengamatan data dilakukan secara langsung melalui kegiatan di lapang (data primer) dan secara tidak langsung (data sekunder) yang diperoleh dari arsip perusahaan. Data primer yang diamati meliputi : dominansi jenis gulma, teknik pengendalian gulma, kondisi gulma dominan setelah semprot, evaluasi metode pengendalian gulma, alat pelindung diri (APD), kalibrasi semprot, dan tenaga kerja. Data sekunder yang diamati diantaranya yaitu profil perusahaan, letak geografis dan wilayah administrasi, data iklim curah hujan 7 tahun terakhir, luas areal konsesi (HGU) dan tata guna tanah, keadaan tanaman produksi, struktur organisasi dan ketenagakerjaan, serta data produksi Aneka Persada Estate 5 tahun terakhir.

Data primer dan sekunder dianalisis secara kualitatif dan kuantitatif dengan menggunakan metode analisis deskriptif seperti, analisis Nisbah Jumlah Dominansi, mencari rata-rata persentase hasil pengamatan, dan menggunakan uji $T$ student. Analisis kualitatif adalah membandingkan data aktual yang diperoleh di lapangan dengan studi literatur serta bahan materi selama perkuliahan. Analisis kualitatif dilakukan pada pengamatan aspek khusus. Analisis kuantitatif adalah data yang diperoleh, dianalisis secara kuantitatif dan dihitung secara matematis. Data diuji menggunakan t-student dan dibandingkan terhadap standar perusahaan yang berlaku secara umum, kemudian dilakukan juga studi pustaka untuk membandingkannya. Pada tahap penyemprotan gulma dilakukan pengamatan prestasi kerja realisasi dan dibandingkan dengan standar kerja karyawan, kemudian diuji dengan menggunakan T-student pada taraf $5 \%$ dengan perangkat lunak minitab.

\section{HASIL DAN PEMBAHASAN}

\section{Kondisi Umum}

Aneka Persada Estate terletak di desa Maredan, kecamatan Tualang, kabupaten Siak, Riau. Menurut klasifikasi Schmidth-Ferguson, Aneka Persada Estate memiliki nilai Q sebesar $7.58 \%$ yang menandakan bahwa kebun APE memiliki iklim tipe A atau sangat basah. Tercatat pada periode 2010-2017 curah hujan tahunan berkisar antara $1816 \mathrm{~mm}-3355 \mathrm{~mm}$, dengan curah hujan rata-rata tahunannya adalah 2442.40 $\mathrm{mm}$ dan curah hujan rata-rata bulanannya yaitu
$222.38 \mathrm{~mm}$. Hari hujan rata-rata tahunan di kebun APE adalah 121.14 hari dan hari hujan rata-rata bulanannya yaitu 10.88 atau 11 hari. Suhu udara harian di APE antara $20-35^{\circ} \mathrm{C}$. Kelembaban udara rata-rata mencapai $80 \%$. Lama penyinaran matahari di kebun maksimal 12 jam per hari.

Aneka Persada Estate terletak pada 10 $100 \mathrm{~m}$ dpl dan mempunyai dua jenis lahan, yaitu lahan mineral dan lahan gambut. Tingkat kematangan gambut APE adalah hemis sampai safris sehingga sesuai untuk budidaya kelapa sawit. Lahan mineral seluas 3333.38 ha (91.66 $\%$ ), sedangkan lahan gambut seluas 278.26 ha $(8.34 \%)$ dari total luas kebun. Bentuk topografi bermacam-macam dengan topografi datar (flat) kemiringan $0-4 \%$ luas areal 286.06 ha, bergelombang (undulating) kemiringan $4-12 \%$ luas areal 720.95 ha dan berbukit (hilly) kemiringan $12-38 \%$ luas areal 2559.92 ha. Jenis tanah yang ada di Aneka Persada Estate adalah ultisol yang berasal dari bahan induk alluvial dengan tekstur liat berpasir (sandy clay). Areal konsesi dibagi menjadi empat divisi. Luas divisi I yaitu 1006.18 ha, luas divisi II yaitu 813.04 ha, luas divisi III yaitu 948.91 ha, dan luas divisi IV yaitu 848.17 ha. Total luas lahan yang sudah ditanami kelapa sawit yaitu 3616.29 ha. Luas lahan yang tidak ditanami terdiri dari bangunan, jalan, jembatan, pabrik, parit, rawa, lahan konservasi, okupasi, dan areal lainnya dengan luas total yaitu 818.32 ha.

Aneka Persada Estate menggunakan bibit kelapa sawit yang berasal dari varietas Tenera (Dura x Picifera). Jenis yang digunakan adalah Marihat, Socfindo, Lonsum, dan Damimas. Minamas Research Center (MRC) juga sedang mengembangkan varietas sendiri yang harapannya dapat diterima oleh masyarakat. Pola tanam yang digunakan adalah menggunakan mata lima $(9.2 \mathrm{~m}$ x $9.2 \mathrm{~m}$ ) sehingga populasi rata-ratanya adalah 136 tanaman $\mathrm{ha}^{-1}$. Saat ini, divisi III Aneka Persada Estate sedang melakukan replanting pada blok D020, E020, E021, dan F020 dan akan menggunakan pola tanam terasan pada daerah berbukit dengan jarak 26 feet (7.92 m) untuk jarak dalam teras dan 28 feet $(8.53 \mathrm{~m})$ untuk jarak antar teras sehingga per ha akan didapatkan 148 tanaman $\mathrm{ha}^{-1}$. Pada daerah rendahan jarak tanamnya 23 feet $\mathrm{x} 26$ feet sehingga dalam satu ha didapatkan total pkk yaitu 180 tanaman $\mathrm{ha}^{-1}$.

\section{Teknik Pengendalian Gulma}

Perkebunan kelapa sawit harus menerapkan komponen pengendalian gulma terpadu dengan memberdayakan seluruh komponen pengendalian, meliputi cara kultur teknis, biologi, preventif, dan pengendalian kimiawi secara selektif dan spesifik 
dengan memperhatikan kelestarian lingkungan (Rambe et al., 2010). Berikut adalah teknik pengendalian gulma yang digunakan kebun Aneka Persada.

Pengendaian Gulma Secara Manual. Pengendalian gulma secara manual terdiri dari rawat piringan manual, gawangan manual (babat), Dongkel Anak Kayu (DAK), dan rawat kacangan. Pengendalian gulma secara manual dilakukan dengan menggunakan parang, parang babat, dan cados (cangkul dodos). Rawat piringan manual dilakukan setelah dilakukan semprot piringan TM. Piringan di sekitar tanaman kelapa sawit harus bebas gulma atau dikenal dengan zona W0 sehingga mudah dalam menentukan buah masak, pengutipan brondolan, dan mengurangi kompetisi unsur hara dan air karena akar halus tanaman masih berada di sekitar pokok.

Pekerjaan yang dilakukan pada babat gawangan yaitu membabat tanaman pakis yang biasanya terdiri dari tiga jenis pakis, yaitu pakis kawat (Dicrapnoteris linearis), pakis (Nephrolepis bisserata), dan pakis udang (Stenoclaena palustris). Pekerjaan membabat hanya dilakukan pada pakis yang tumbuh tinggi dan semak serta tidak dibabat seluruhya. Hal ini dikarenakan tumbuhan pakis dapat menjaga kelembaban tanah dan mengurangi laju air (run off). Dongkel anak kayu dikhususkan untuk gulma yang berkayu yang tumbuh besar. Kegiatan ini biasanya dilakukan bersama dengan pengendalian gulma di gawangan. Jenis-jenis gulma berkayu di APE adalah Solanum carolinense, Melastoma malabathricum, Clidemia hirta, Cakar elang, dsb.

Pengendaian Gulma Secara Kimia. Pengendalian gulma kimia dapat dibedakan menjadi dua yaitu pengendalian di piringan dan gawangan. Tidak semua gulma di gawangan harus diberantas, misalnya pakis Nephrolepis bisserata, Cassia cobanensis, Euphorbia sp., Turnera subulata yang dapat berfungsi sebagai inang musuh alami hama-hama kelapa sawit (beneficial plant). Pengendalian gulma di piringan mempunyai tujuan untuk mengurangi kompetisi hara dan air, meningkatkan efisiensi pemupukan, mempermudah kontrol pelaksanaan panen, dan pengutipan brondolan. Tujuan pengendalian gulma di gawangan mengurangi kompetisi hara, air dan sinar matahari serta mempermudah kontrol pekerjaan dari satu gawangan ke gawangan lain, menekan populasi hama (terutama pada TBM).

Pengendalian gulma pada tanaman TM muda dan TBM menggunakan alat knapsack sprayer kapasitas 121 , sedangkan pada TM tua menggunakan alat MHS (Micron Herbi Sprayer) kapasitas 101 . Kerugian alat MHS adalah alat ini peka terhadap kerusakan, sehingga harus secara teratur dikaliberasi dan harus dibersihkan setelah pemakaian. Herbisida yang berbahan aktif paraquat tidak direkomendasikan untuk disemprotkan dengan alat semprot CDA, karena sangat berbahaya yang dapat menyebabkan kerusakan organ tubuh seperti hati, paru - paru, jantung, ginjal dalam hitungan hari. Herbisida, dosis dan konsentrasi yang digunakan APE dapat dilihat pada Tabel 1.

Pengendaian Gulma Kultur Teknis. Metode pengendalian gulma secara kultur teknis merupakan tindakan atau cara pengendalian gulma dengan memperhatikan segi ekologis atau keadaan lingkungan tanaman budidaya agar menciptakan lingkungan yang menguntungkan bagi pertumbuhan tanaman sehingga tanaman dapat bersaing dengan gulma. Metode pengenda-

Tabel 1. Kegiatan semprot di kebun Aneka Persada

\begin{tabular}{|c|c|c|c|c|c|c|c|}
\hline No & Kegiatan & Herbisida & Bahan aktif & Konsentrasi & $\begin{array}{c}\text { herbisida } \\
\text { per kap }\end{array}$ & $\begin{array}{l}\text { Dosis } \\
\text { per ha }\end{array}$ & $\begin{array}{l}\text { Basis } \\
\text { Kerja }\end{array}$ \\
\hline 1 & $\begin{array}{l}\text { Semprot } \\
\text { piringan MHS }\end{array}$ & $\begin{array}{l}\text { Ken-UP/Becano } \\
+ \text { Kenlly }\end{array}$ & $\begin{array}{l}\text { Isopropilamina glifosat } \\
480 \mathrm{gl}^{-1} / \text { indaziflam } \\
500 \mathrm{gl}^{-1}+\text { Metil } \\
\text { metsulfuron } 20 \%\end{array}$ & $\begin{array}{l}2,50 \%+ \\
0,125 \%\end{array}$ & $\begin{array}{l}250 \mathrm{ml}+ \\
12,5 \mathrm{~g}\end{array}$ & $\begin{array}{l}250 \mathrm{ml}+ \\
12,5 \mathrm{~g}\end{array}$ & 4 ha \\
\hline 2 & $\begin{array}{l}\text { Semprot } \\
\text { piringan } \mathrm{RB}\end{array}$ & Ken-Up +Kenlly & $\begin{array}{l}\text { Isopropilamina glifosat } \\
480 \mathrm{gl}^{-1}+\text { Metil } \\
\text { metsulfuron } 20 \%\end{array}$ & $\begin{array}{l}0,67 \%+ \\
0,025 \%\end{array}$ & $\begin{array}{l}80 \mathrm{ml}+ \\
3 \mathrm{~g}\end{array}$ & $\begin{array}{l}115 \mathrm{ml}+ \\
4,5 \mathrm{~g}\end{array}$ & 2 ha \\
\hline 3 & $\begin{array}{l}\text { Semprot } \\
\text { gawangan }\end{array}$ & $\begin{array}{l}\text { Ken-UP + } \\
\text { Kenlly }\end{array}$ & $\begin{array}{l}\text { Isopropilamina glifosat } \\
480 \mathrm{gl}^{-1}+\text { Metil } \\
\text { metsulfuron } 20 \%\end{array}$ & $\begin{array}{l}0,67 \%+ \\
0,03 \%\end{array}$ & $\begin{array}{l}80 \mathrm{ml}+ \\
4 \mathrm{~g}\end{array}$ & $\begin{array}{l}400 \mathrm{ml}+ \\
20 \mathrm{~g}\end{array}$ & 2,5 ha \\
\hline 4 & $\begin{array}{l}\text { Spot spraying } \\
\text { lalang }\end{array}$ & Ken-Up & $\begin{array}{l}\text { Isopropilamina glifosat } \\
480 \mathrm{gl}^{-1}\end{array}$ & $1,12 \%$ & $135 \mathrm{ml}$ & $\begin{array}{l}500- \\
1.000 \mathrm{ml}\end{array}$ & 5 ha \\
\hline 5 & $\begin{array}{l}\text { Spot spraying } \\
\text { anak kayu }\end{array}$ & Kenlon & $\begin{array}{l}\text { triclopir butoksi etil } \\
\text { ester } 480 \mathrm{gl}^{-1}\end{array}$ & $0,67 \%$ & $80 \mathrm{ml}$ & $450 \mathrm{cc}$ & 2,5 ha \\
\hline 6 & $\begin{array}{l}\text { Semprot } \\
\text { blanket }\end{array}$ & Ken-Up +Kenlly & $\begin{array}{l}\text { Isopropilamina glifosat } \\
480 \mathrm{gl}^{-1}+\text { Metil } \\
\text { metsulfuron } 20 \%\end{array}$ & $\begin{array}{l}0,67 \%+ \\
0,03 \%\end{array}$ & $\begin{array}{l}80 \mathrm{ml}+ \\
4 \mathrm{~g}\end{array}$ & $\begin{array}{l}400 \mathrm{cc}+ \\
20 \mathrm{~g}\end{array}$ & 2 ha \\
\hline
\end{tabular}


lian kultur teknis Aneka Persada Estate dilakukan pada saat penanaman awal dengan cara menanam kacangan sebagai tanaman penutup tanah. Kacangan yang ditanam diantaranya adalah Pueraria javanica, Centrocema pubescens, Mucuna bracteata, dsb.

Pengendaian Gulma Mekanis. Kegiatan tersebut dilakukan dengan cara merusak fisik atau bagian gulma sehingga pertumbuhannya menjadi terhambat dan akhirnya mati. Metode pengendalian ini memiliki prinsip yang sama dengan pengendalian gulma manual, hanya saja menggunakan bantuan mesin untuk pengendaliannya. Kebun Aneka Persada memakai mesin babat untuk mengendalikan gulma sekitar pemukiman masyarakat, jalan utama menuju kantor-kantor divisi dan fasilitas kebun seperti lapangan sepak bola untuk menjaga estetika.

\section{Pengorganisasian Kerja}

Pengisian tangki air dilakukan oleh sopir dan tukang air pada sore hari. Sumber air dapat menggunakan air yang ada di traksi atau sumur yang bersih airnya. Sebelum membuat bon permintaan racun, asisten wajib melihat kondisi atau kerapatan gulma di blok yang akan disemprot. Pencampuran racun harus disaksikan oleh asisten atau senior asisten. Surat permintaan racun sudah harus dibuat 1 hari sebelumnya dan petugas gudang harus hadir sebelum pukul 06.00 WIB.

Kendaraan unit semprot sudah harus standby di gudang sebelum pukul 06.00. Pengadukan larutan harus merata dengan pengaduk dari kayu. Unit semprot harus sudah siap beroperasi pada pukul 06.30. Setiap karyawan diwajibkan membawa alat kerja untuk BTP (cados) sebagai cadangan apabila hari hujan. Mandor bertanggung jawab atas keberadaan alatalat tersebut.

Areal yang disemprot adalah piringan, pasar rintis, rintis tengah, dan TPH. Pengancakan kerja untuk alat semprot yang hanya dapat menjangkau setengah pasar rintis, dilakukan dari rintis tengah terlebih dahulu. Setelah sampai di collection road (CR), tangki diisi lagi dengan larutan dan penyemprotan dilanjutkan pada blok sebelahnya. Untuk alat semprot yang dapat menjangkau 1 pasar rintis, pengancakan dilakukan dari CR sampai CR selanjutnya. Kendaraan harus berpindah ke CR selanjutnya segera setelah selesai pengancakan.

Setiap selesai pekerjaan semprot, mandor wajib melaporkan pemakaian racun, lahan yang disemprot, dan output per HK kepada krani divisi. Buku kegiatan mandor harus diparaf oleh asisten divisi yang bersangkutan setiap harinya dan diketahui oleh askep setiap selesai program di rayonnya.

\section{Vegetasi Gulma}

Dominansi gulma di suatu pertanaman dapat diketahui melalui kegiatan penilaian gulma. Informasi mengenai gulma dominan yang diperoleh dari kegiatan penilaian gulma berpengaruh langsung terhadap pengambilan kebijakan pengendalian gulma khususnya mengenai cara, alat, dan bahan yang digunakan agar pengendalian gulma menjadi efisien dan efektif.

Pengamatan penilaian gulma dilakukan pada 6 blok, yaitu blok E019 (2016), D014 (2013), D015 (2013), G021 (1999), E022 (1997), dan D023 (1996). Distribusi petak contoh yang digunakan adalah sampling beraturan, yaitu 30 petak contoh pada 5 pasar pikul. Masing-masing pasar pikul diambil 6 petak contoh (3 piringan dan 3 pasar pikul) dengan menggunakan metode kuadrat berukuran $50 \mathrm{~cm}$ x $50 \mathrm{~cm}$. Nisbah Jumlah Dominansi (NJD) adalah gambaran kemampuan suatu jenis gulma tertentu untuk menguasai sarana tumbuh yang ada. Tingginya persentase nilai NJD berpengaruh langsung terhadap tingginya dominansi suatu jenis gulma. Adapun cara perhitungan NJD adalah sebagai berikut:

$$
N J D=\frac{K N+F N}{2}
$$

KN (Kerapatan Nisbi) adalah nilai KM spesies gulma tertentu dibagi total KM semua jenis gulma. FN (frekuensi nisbi) adalah nilai FM spesies gulma tertentu dibagi total FM semua jenis gulma. NJD mengindikasikan kemampuan penguasaan sarana tumbuh yang ada oleh suatu jenis gulma tertentu. Gulma yang dominan pada kebun Aneka Persada berturut-turut yaitu Asystasia intrusa $15.08 \%$, Digitaria ciliaris 6.42 $\%$, Borreria alata $6.23 \%$, Mucuna bracteata $6.23 \%$, dan Centoteca lapacea $5.54 \%$.

Koefisien komunitas adalah nilai yang menggambarkan kesamaan pola komunitas gulma antara satu areal dengan areal lain. Hasil penilaian dominansi gulma dijadikan dasar dalam membandingkan nilai kerapatan gulma sehingga diperoleh koefisien komunitasnya. Koefisien komunitas yang nilainya $>70 \%$ menunjukkan bahwa vegetasi antara satu areal dengan areal lain relatif homogen (Santosa et al. 2009). Nilai koefisien komunitas dari 4 areal yang telah dilakukan analisis vegetasi disajikan dalam Tabel 2. 
Tabel 2. Hasil pengamatan nilai KK (Koefisien Komunitas)

\begin{tabular}{lccccc}
\hline \multirow{2}{*}{ Blok tahun tanam } & \multicolumn{5}{c}{ Koefisien komunitas (\%) } \\
\cline { 2 - 6 } & D015 (2013) & D014 (2013) & G021 (1999) & E022 (1997) & D023 (1996) \\
\hline E019 (2016) & 65.45 & 53.41 & 52.65 & 56.05 & 37.97 \\
D015 (2013) & - & 52.66 & 50.20 & 52.50 & 41.04 \\
D014 (2013) & - & - & 51.63 & 51.56 & 44.63 \\
G021 (1999) & - & - & - & 55.16 & 68.20 \\
E022 (1997) & - & - & - & - & 52.98 \\
\hline
\end{tabular}

Rata-rata

52.41

Berdasarkan hasil pengamatan pada Tabel 2, dinyatakan bahwa gulma yang ada di APE relatif tidak homogen, yang artinya di areal tersebut memiliki gulma dengan spektrum yang luas. Berdasarkan pemilihan herbisida, APE sudah cukup baik dalam memilih herbisida yaitu untuk areal lahan yang memiliki gulma dengan spektrum yang luas perlu dilakukan pencampuran herbisida. Menurut penelitian Wijaya dan Nusyirwan (2013) pencampuran herbisida dapat meningkatkan efektivitas herbisida dalam mengendalikan gulma di perkebunan kelapa sawit.

\section{Pengamatan Kondisi Gulma}

Pengamatan Asystasia intrusa dilakukan di blok E019 tahun tanam 2016. Pengamatan dimulai sejak aplikasi semprot pada 8 April - 29 April 2017. Asystasia intrusa mati setelah 3 MSA (minggu setelah aplikasi) penyemprotan herbisida berbahan aktif isopropilamina glifosat $480 \mathrm{~g}$ $l^{-1}+$ metil metsulfuron $20 \%$ dengan dosis

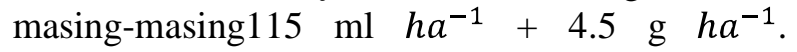
Menurut Prawirosukarto et al. (2005) biji Asystasia intrusa mampu tumbuh dalam waktu 30 hari dengan viabilitas $85 \%$. Tunas pada ruas batang akan mampu tumbuh setelah tunas tersebut menyentuh tanah. Hasil pengamatan kondisi setelah semprot gulma A.intrusa dapat dilihat pada Tabel 3.

Pencampuran isopropilamina glifosat 115

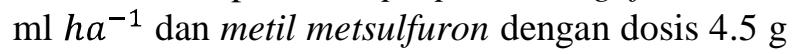
$h a^{-1}$ memiliki pengaruh terhadap perubahan fisik atau morfologis gulma yang hidup di piringan sawit. Hal ini dapat dilihat pada Tabel 3, mulai dari 14 HSA pada parameter kesegaran, kondisi A.intrusa sudah tidak segar berganti menjadi kondisi yang sudah layu dan mengkerut hingga pada 21 HSA tumbuhan sudah $95 \%$ mengkerut. Pada parameter warna, A.intrusa yang awalnya $100 \%$ masih berwarna hijau tua, mulai memudar warnanya berturut - turut dari hijau tua, hijau muda, kuning, dan hitam (kering). Menurut Antralina et al (2015), dua strategi efektif dalam pengendalian secara kimiawi adalah dengan melakukan rotasi herbisida dan adanya pencampuran penggunaan herbisida.

\section{Kalibrasi Semprot}

Kegiatan kalibrasi alat merupakan salah satu kontrol yang dapat menggambarkan bagaimana teknis penyemprotan dilakukan di lapang. Kondisi alat semprot yang baik akan mempengaruhi keberhasilan pengendalian gulma (Pakpahan, 2016). Kalibrasi alat semprot pada Knapsack sprayer dan MHS dapat dilihat pada Tabel 4, sedangkan rekapitulasi hasil uji beda nilai tengah kalibrasi semprot pada dua alat semprot dapat dilihat pada Tabel 5.

Berdasarkan pengamatan yang telah dilakukan, dapat diketahui pada Tabel 4 bahwa prestasi kerja menggunakan alat semprot MHS tidak sesuai dengan basis kerja yang ditentukan perusahaan yaitu sebesar 4 ha. Hal ini disebabkan karena beberapa faktor salah satunya adalah waktu kerja yang terkadang baru dimulai pukul 8 pagi (dalam SOP perusahaan, yaitu pukul 7 pagi). Penggunaan alat semprot Knapsack sprayer ber-

Tabel 3. Pengamatan kondisi gulma Asystasia intrusa

\begin{tabular}{llllllllr}
\hline Ciri Fisik & Hari ke-1 & $\%$ & Hari ke-7 & $\%$ & Hari ke-14 & $\%$ & Hari ke-21 & $\%$ \\
\hline Kesegaran & Segar & 100 & Segar & 20 & Layu & 30 & Layu & 5 \\
& & & Layu & 80 & Mengkerut & 70 & Mengkerut & 95 \\
\hline Warna & Hijau tua & \multirow{2}{*}{100} & Hijau Tua & 30 & Hijau tua & 0 & Hijau tua & 0 \\
& & & Hijau muda & 60 & Hijau muda & 20 & Hijau muda & 0 \\
& & & Kuning & 10 & Kuning & 50 & Kuning & 5 \\
& & & & Hitam & 30 & Hitam & 95 \\
\hline
\end{tabular}


Tabel 4. Kalibrasi alat semprot

\begin{tabular}{|c|c|c|c|c|c|c|}
\hline \multirow[b]{2}{*}{$\begin{array}{l}\text { Tenaga } \\
\text { Kerja }\end{array}$} & \multicolumn{3}{|c|}{ Micron Herbi Sprayer } & \multicolumn{3}{|c|}{ Knapsack sprayer } \\
\hline & $\begin{array}{l}\text { Flowrate } \\
\text { (ml/menit) }\end{array}$ & $\begin{array}{l}\text { Kecepatan } \\
\text { Jalan } \\
\text { (m/menit) }\end{array}$ & $\begin{array}{c}\text { Prestasi } \\
\text { Kerja (Ha) }\end{array}$ & $\begin{array}{l}\text { Flowrate } \\
\text { (ml/menit) }\end{array}$ & $\begin{array}{c}\text { Kecepatan } \\
\text { Jalan }(\mathrm{m} / \mathrm{menit})\end{array}$ & $\begin{array}{c}\text { Prestasi } \\
\text { Kerja (Ha) }\end{array}$ \\
\hline TK 1 & 279.19 & 33.08 & 3.91 & 436.89 & 17.13 & 2.41 \\
\hline TK 2 & 333.33 & 36.06 & 3.44 & 514.14 & 19.42 & 1.96 \\
\hline TK 3 & 322.58 & 30.57 & 3.59 & 473.06 & 18.29 & 2.09 \\
\hline TK 4 & 303.03 & 34.55 & 3.59 & 510.64 & 17.45 & 2.28 \\
\hline TK 5 & 297.62 & 34.22 & 3.53 & 451.69 & 20.23 & 2.48 \\
\hline Total & 1535.75 & 168.48 & 18.06 & 2386.42 & 92.52 & 11.22 \\
\hline Rata-rata & 307.15 & 33.70 & $3.61 * *$ & 477.28 & 18.50 & $2.24^{t n}$ \\
\hline
\end{tabular}

Keterangan: Target kerja MHS $4 \mathrm{Ha} H K^{-1}$, sedangkan untuk Knapsack sprayer yaitu $2 \mathrm{Ha} H K^{-1}$

Tabel 5. Rekapitulasi hasil uji beda nilai tengah kalibrasi semprot pada dua alat semprot

\begin{tabular}{cccc}
\hline \multirow{2}{*}{ Parameter } & \multicolumn{2}{c}{ Alat semprot } & \multirow{2}{*}{ t-hitung } \\
\cline { 2 - 3 } & Micron Herbi Sprayer & $\mathbf{5 1 4 . 1 4} \pm \mathbf{4 3 6 . 8 9}$ & $-9.37^{* *}$ \\
$\begin{array}{c}\text { Flowrate } \\
\text { (ml/menit) }\end{array}$ & $333.33 \pm 279.19$ & $20.23 \pm 17.13$ & $13.98^{* *}$ \\
$\begin{array}{c}\text { Kecepatan jalan } \\
\text { (m/menit) }\end{array}$ & $\mathbf{3 6 . 0 6} \pm \mathbf{3 0 . 5 7}$ & $2.48 \pm 1.96$ & $10.90^{* *}$ \\
\hline Prestasi Kerja (Ha) & $\mathbf{3 . 9 1} \pm \mathbf{3 . 4 4}$ &
\end{tabular}

Keterangan: $* *=$ Berbeda sangat nyata, $\mathrm{tn}=$ Tidak berbeda nyata

dasarkan hasil uji beda nilai tengah dapat disimpulkan bahwa penggunaan Knapsack sprayer sudah sesuai dengan basis kerja sebesar 2 ha.

Parameter flowrate, kecepatan jalan, dan prestasi kerja antara MHS dan Knapsack sprayer juga dilakukan uji beda nilai tengah. Dapat disimpulkan dari ketiga parameter yang telah diuji pada Tabel 5, bahwa penggunaan MHS lebih efektif dan efisien daripada penggunaan knapsack sprayer karena luasan semprot yang dapat dicakup menjadi lebih luas. Menurut Yulianto et al. (2017), penggunaan knapsack sprayer memiliki kekurangan salah satunya yaitu kondisi kematian gulma yang kurang merata.

\section{Penggunaaan APD (Alat Pelindung Diri)}

Tenaga kerja pengendalian gulma khususnya tenaga semprot diharuskan untuk memakai APD yang lengkap, tak terkecuali untuk tenaga pengangkut air dan mandor. Tapi pada kenyataannya dilapang, masih saja terdapat tenaga kerja yang tidak memakainya dengan lengkap. APD yang diharuskan untuk digunakan saat digunakan dilapang yaitu masker, apron, topi atau penutup kepala, sarung tangan, sepatu, dan kacamata (Minamas, 2013). Penulis melakukan pengamatan penggunaan APD yang dilakukan oleh tenaga semprot. Pengamatan penggunaan APD dapat dilihat pada Tabel 6.

Tabel 6. Pengamatan penggunaan APD tenaga semprot piringan MHS

\begin{tabular}{|c|c|c|c|c|c|c|c|c|}
\hline \multirow[b]{2}{*}{ Pengamatan } & \multicolumn{7}{|c|}{ Jenis APD } & \multirow[b]{2}{*}{ Ket } \\
\hline & Kriteria & Topi & $\begin{array}{l}\text { Kaca } \\
\text { mata }\end{array}$ & Masker & $\begin{array}{l}\text { Sarung } \\
\text { tangan }\end{array}$ & Apron & Boots & \\
\hline \multirow{2}{*}{1} & Pakai & 10 & 0 & 8 & 10 & 10 & 10 & \\
\hline & Tidak & 0 & 10 & 2 & 0 & 0 & 0 & $01 / 04 / 2017$ \\
\hline \multirow{2}{*}{2} & Pakai & 7 & 0 & 5 & 7 & 7 & 7 & \\
\hline & Tidak & 0 & 7 & 2 & 0 & 0 & 0 & $15 / 04 / 2017$ \\
\hline \multirow{2}{*}{3} & Pakai & 10 & 10 & 10 & 10 & 10 & 10 & \\
\hline & Tidak & 0 & 0 & 0 & 0 & 0 & 0 & 03/05/2017 \\
\hline \multirow{2}{*}{4} & Pakai & 6 & 6 & 6 & 6 & 6 & 6 & \\
\hline & Tidak & 0 & 0 & 0 & 0 & 0 & 0 & $12 / 05 / 2017$ \\
\hline \multirow{2}{*}{ Total } & Pakai & 33 & 16 & 29 & 33 & 33 & 33 & \\
\hline & Tidak & 0 & 17 & 4 & 0 & 0 & 0 & \\
\hline \multicolumn{2}{|c|}{ Total HK } & 33 & 33 & 33 & 33 & 33 & 33 & \\
\hline \multicolumn{2}{|c|}{ Persentase } & 100 & 48.48 & 87.88 & 100 & 100 & 100 & \\
\hline \multicolumn{2}{|c|}{ Rata-rata persentase } & \multicolumn{6}{|c|}{89.39} & \\
\hline
\end{tabular}


Hasil pengamatan yang ditunjukkan pada Tabel 6, umumnya tenaga semprot jarang memakai kacamata keselamatan. Kacamata tersebut jarang digunakan dengan alasan menyulitkan pemandangan karena uap yang keluar dari pernapasan membuat permukaan kaca berembun. Hal ini mungkin dapat diatasi dengan perubahan desain pada kacamata, salah satunya dapat digunakan model tameng muka (face shield). Tidak seperti tameng muka yang digunakan oleh juru las bengkel, namun cukup menggunakan kaca anti embun dikombinasikan dengan helm pelindung pada APD yang dapat dibuka dan ditutup dengan mudah. Menurut Bintoro (2010), bentuk dari pelindung muka bermacam-macam salah satunya dapat berbentuk helmet.

\section{Faktor-faktor yang Mempengaruhi Komunitas Gulma}

Kultur Teknik. APE melakukan kegiatan pengolahan tanah, pemupukan, dan diversifikasi tanaman untuk menekan komunitas gulma. Berdasarkan pengamatan di lapangan, pengolahan tanah dilakukan saat pembukaan lahan dan sebelum penanaman dengan menggunakan alatalat mekanis. Pemupukan dilakukan secara intensif, baik pada TM maupun tanaman sisipan. Diversifikasi tanaman dilakukan dengan menanam LCC pada bahu jalan dan pada gawangan. Menurut Caamal-Maldonado et al. (2001) bahwa legum penutup tanah dapat menghambat perkecambahan gulma melalui penutupannya dan menghambat pertumbuhan gulma karena kandungan alelopati serta dapat meningkatkan kesuburan tanah dan mencegah erosi.

Tanaman. Hasil pengamatan di lapangan diperoleh bahwa jarak tanam kelapa sawit di Aneka Persada Estate cukup lebar (9.2 m x $9.2 \mathrm{~m}$ ) dan tidak teratur sehingga komunitas gulma meningkat. Gulma dapat tumbuh dengan baik pada areal TM yang terdapat pokok mati karena tidak adanya tajuk yang saling menutupi sehingga banyak cahaya matahari yang masuk dan memberikan energi pada gulma untuk terus tumbuh. Pada areal TM yang tajuknya telah saling menutup rapat tanpa ada pokok mati, komunitas gulma tertekan karena tajuk saling menutup sehingga tidak ada cahaya matahari yang masuk. Menurut Hakim (2007) kelapa sawit akan mempunyai masalah gulma yang serius jika jarak tanam lebar, karena cahaya matahari leluasa mencapai permukaan tanah yang kaya dengan potensi gulma.
Lingkungan. Sastroutomo

(1990) menyatakan bahwa, faktor-faktor klimatik yang menentukan pertumbuhan, reproduksi, dan distribusi gulma adalah cahaya, temperatur, angin, air dan aspek-aspek musiman dari faktor-faktor tersebut. Daerah yang memiliki curah hujan tinggi memiliki pertumbuhan gulma yang cepat, beragam, dan kerapatannya tinggi.

Menurut klasifikasi Schmidth-Ferguson, Aneka Persada Estate memiliki nilai Q sebesar $7.58 \%$ yang menandakan bahwa kebun APE memiliki iklim tipe A atau sangat basah. Hal tersebut dapat menyebabkan gulma dapat mudah tumbuh karena kelembaban tanah yang tinggi. Kondisi iklim di APE tersebut dapat mendukung pertumbuhan gulma.

Faktor-faktor yang Mempengaruhi Keberhasilan Pengendalian Gulma

Faktor Iklim. Faktor iklim yang berpengaruh langsung adalah curah hujan. Intensitas curah hujan yang tinggi akan menghambat kegiatan pengendalian gulma secara kimia. Hal ini mengakibatkan adanya areal yang tertinggal atau belum dikerjakan. Kelembaban udara yang tinggi dan hujan yang turun setelah aplikasi semprot mempengaruhi kualitas semprotan dengan tingkat kematian yang rendah. Pengendalian gulma tidak bisa dilaksanakan pada hari hujan, karena hujan akan mencuci herbisida sehingga keefektifan kerja herbisida berkurang. Untuk mendapatkan hasil yang baik, minimum 6 jam setelah aplikasi tidak terjadi hujan (Minamas, 2013). Hasil pengamatan dilapang terkadang mandor tetap mengintruksikan untuk melaksanakan penyemprotan walaupun kondisi sedang hujan. Hal ini tentu berdampak pada hasil semprot yang tidak efektif.

Kondisi Lapangan. Kebun APE menerapkan sistem koservasi tanah dan air terhadap dampak erosi yang ditimbulkan oleh pengendalian gulma dengan cara tidak melakukan pengendalian gulma menyeluruh terhadap gulma Nephrolepis bisserata yang bermanfaat untuk mengurangi erosi akibat aliran permukaan (run off). Hasil pengamatan lapangan menunjukkan kondisi jalan yang tidak baik, utamanya saat hujan turun deras pada hari sebelumnya. Hal ini berdampak pada jalan yang licin ataupun banjir sehingga mobil semprot yang biasa membawa tenaga kerja semprot MHS akan beresiko terpuruk di lapangan.

Alat dan Bahan. Ketersediaan alat, keterlambatan penyediaan dan penyaluran bahan berpengaruh terhadap rencana kerja pengendalian. Hasil pengamatan lapangan menunjukkan 
beberapa masalah pada kondisi kendaraan semprot dan juga peralatan, terutama peralatan semprot yang kurang memadai. Selain itu ketersediaan air bersih di lapangan yang sedikit membuat pekerja harus mencari sumber air terlebih dahulu, sehingga membuat waktu kerja semakin sedikit dan target kerja tidak terpenuhi. Menurut Anggraeni (2015), ketersediaan air bersih di lapang akan mempengaruhi keberhasilan pengendalian gulma.

Sumber Daya Manusia. Ketersediaan tenaga kerja dan kualitas tenaga kerja terutama keterampilan penggunaan dan perawatan alat berpengaruh terhadap keberhasilan pengendalian. Beberapa pekerja di APE terkadang tidak menggunakan alat pelindung diri (APD) selama proses penyemprotan herbisida berlangsung tak terkecuali saat pencampuran bahan herbisida dengan alasan penggunaan APD membuat menjadi sulit bergerak seperti penggunaan kacamata dan masker. Tjitrosoedirdjo et al. (1984), bahwa keterampilan dan penguasaan kerja sangat menentukan keberhasilan pengendalian gulma.

Pengendalian gulma di lapangan memerlukan pengetahuan dan wawasan yang luas dari pengelola perkebunan. Perlu peran tegas dari pemimpin di lapangan seperti mandor, mandor 1, dan juga asisten divisi agar tenaga semprot lebih memahami arti penting kesehatan dan keselamatan kerja. Pengendalian gulma harus dilaksanakan secara efektif dan efisien sehingga dihasilkan pengendalian gulma yang tepat sasaran dan biaya yang dikeluarkan dapat diminimalisir.

Rotasi Pengendalian. Rotasi pengendalian gulma sangat berpengaruh terhadap perkembangan komunitas gulma dilapang. Jika rotasi pengendalian dilakukan tidak tepat waktu, perkembangan gulma akan semakin padat. Rotasi pengendalian gulma untuk daerah piringan yaitu setiap 4 bulan sekali TM tua, 3 bulan sekali pada TM muda, dan 2 bulan sekali pada TBM, rotasi pengendalian gulma untuk spot spraying dan gawangan yaitu 2 bulan sekali.
Hasil pengamatan yang telah dilakukan, masih terdapat rotasi pengendalian gulma yang tidak tepat waktu, terutama pada areal TBM dan TM1 yang ditanam Mucuna bracteata. Jenis kacangan ini memang sengaja ditanam, namun membutuhkan pengendalian yang rutin karena perkembangannya yang sangat cepat. Menurut penelitian yang telah dilakukan oleh Yanto (2017) bahwa perkembangan Mucuna bracteata dapat dihambat melalui penggunaan paclobutrazol yang mampu menghambat pertumbuhan panjang sulur dan bobot keringnya dengan konsentrasi 100 ppm dan 200 ppm dan diaplikasikan dengan menggunakan sprayer pada seluruh bagian tajuk M.bracteata secara merata.

\section{Evaluasi Metode Pengendalian Gulma}

Evaluasi metode pengendalian gulma diperlukan dalam menentukan kesesuaian kegiatan pengendalian yang berprinsip pada lima tepat. Prinsip lima tepat pada kebun APE dapat dilihat pada Tabel 7.

Pengendalian gulma di kebun Aneka Persada sudah cukup sesuai dengan prinsip $5 \mathrm{~T}$. Hanya saja pada parameter tepat waktu terdapat beberapa kegiatan yang tidak memenuhi standar kerja yang telah ditetapkan. Kegiatan dongkel anak kayu dan babat gawangan seharusnya dilaksanakan setiap 2 bulan sekali, namun pada aktualisasinya di lapang hal ini sangat sulit diterapkan karena kurangnya tenaga kerja. Kegiatan semprot piringan, pasar pikul, gawangan, dan TPH memiliki rotasi pengendalian yang berbeda. Aktualisasi yang ada dilapang, ada beberapa blok yang sudah mencapai rotasi yang ditentukan, namun ada beberapa blok yang kurang sesuai. Salah satu cara yang dapat dilakukan untuk mengatasi rotasi pengendalian gulma yang tidak tercapai yaitu dengan penambahan tenaga kerja kontrak yang disediakan dari luar perusahaan (karyawan harian lepas) agar dapat mencapai target kerja yang ingin dicapai kebun.

Tabel 7. Prinsip lima tepat yang diterapkan di kebun APE

\begin{tabular}{|c|c|c|c|c|c|}
\hline${ }_{\text {Kegiatan }}^{\text {Tepat }}$ & Waktu & Jenis & Cara & Tempat & Dosis \\
\hline DAK (dongkel anak kayu) & $\mathrm{X}$ & - & $\sqrt{ }$ & $\sqrt{ }$ & - \\
\hline Babat gawangan & $\mathrm{X}$ & & $\sqrt{ }$ & $\sqrt{ }$ & - \\
\hline $\begin{array}{l}\text { Penyemprotan piringan dan pasar } \\
\text { pikul, dan TPH }\end{array}$ & o & $\overline{\sqrt{ }}$ & $\sqrt{ }$ & $\sqrt{ }$ & $\sqrt{ }$ \\
\hline Penyemprotan gawangan & $\mathrm{O}$ & $\sqrt{ }$ & $\sqrt{ }$ & $\sqrt{ }$ & $\sqrt{ }$ \\
\hline Semprot lalang dan anak kayu & $\sqrt{ }$ & $\sqrt{ }$ & $\sqrt{ }$ & $\sqrt{ }$ & $\sqrt{ }$ \\
\hline
\end{tabular}

Keterangan: $-=$ Tidak ada, $x=$ Tidak sesuai, $\mathrm{o}=$ Kurang sesuai, $\sqrt{ }=$ Sesuai 


\section{KESIMPULAN}

Hasil pengamatan analisis vegetasi yang telah dilakukan bahwa gulma yang dominan pada kebun Aneka Persada yaitu Asystasia intrusa $15.08 \%$, Digitaria ciliaris $6.42 \%$, Borreria alata $6.23 \%$, Mucuna bracteata $6.23 \%$, dan Centoteca lapacea $5.54 \%$. Dan nilai koefisien komunitas gulma di APE relatif tidak homogen. APE sudah cukup baik dalam pemilihan herbisida, untuk areal lahan yang memiliki gulma dengan spektrum yang luas perlu dilakukan pencampuran herbisida. Pertumbuhan Asystasia intrusa dan Mucuna bracteata perlu menjadi perhatian serius pengelola kebun. Perkembangan Mисиna bracteata yang cepat pada areal TBM dan TM 1 dapat dihambat melalui penggunaan paclobutrazol yang mampu menghambat pertumbuhan panjang sulur dan bobot keringnya.

\section{DAFTAR PUSTAKA}

Andika, Widoro. 2013. Berkebun Kelapa Sawit "Si Emas Cair”. AgroMedia Pustaka, Jakarta.

Antralina, M., Istina ,I.N., Yuwariah ,Y., Simarmata T. 2015. Effect of difference weed control methods to yield of lowland rice In the SOBARI. Procedia Food Science. 3:323 329.

Ashton, F.M., Monaco, T.J. 1991. Weed Science Principles and Practices. John Wiley and Sons Inc. New York. 357 p.

Bintoro, W.A. 2010. Faktor yang berhubungan dengan pemakaian pada pengelas di bengkel las listrik kawasan Barito kota Semarang. [Skripsi]. Jurusan Ilmu Kesehatan Masyarakat. Universitas Negeri Semarang. Semarang

Caamal-Maldonado, J.A., Jimenez-Osornio, J.J., Torres-Barrag, A., Anaya , A.L. 2001. The use of allelopathic legume cover and mulch species for weed control in cropping systems. Agron. J. 93: 27-36.

Chikowo, R., Faloya ,V., Petit , S., Munier-Jolain ,N.M. 2009. Integrated weed management systems allow reduced reliance on herbicides and long-term weed control. Agriculture, Ecosystems and Environment. 132:237-242

[Ditjenbun] Direktorat Jenderal Perkebunan. 2013. Pengelolaan Gulma pada Perkebunan Kelapa Sawit. [internet]. [diunduh 2016 Mar 19]. Tersedia pada http://ditjenbun.pertanian.go.id /perlindungan/ berita-196-pengelolaan-gulma pada-perkebunan-kelapa-sawit.html.

[Ditjenbun] Direktorat Jenderal Perkebunan. 2016. Statistik Perkebunan Indonesia 2013-2015 Kelapa Sawit. [internet]. [diunduh 2016 Mar 19]. Tersedia pada http://ditjenbun.deptan. go.id.

Hakim, M. 2007. Agronomis dan Manajemen Kelapa Sawit Buku Pegangan Agronomis dan Pengusaha Kelapa Sawit. Lembaga Pupuk Indonesia. Jakarta.

Martins, B.H., Araujo-Junior, C.F., Miyazawa, M., Vieira, K.M., Milori, D.M.B.P. 2015. Soil organic matter quality and weed diversity in coffee plantation area submitted to weed control and cover crops management. Soil \& Tillage Research. 153:169-174

Minamas. 2013. Minamas Agriculture Reference Manual. Minamas Plantation. Jakarta

Pahan, I. 2008. Panduan Lengkap Kelapa Sawit: Manajemen Agribisnis dari Hulu hingga Hilir. Penebar Swadaya, Jakarta.

Pakpahan, T.H. 2016. Manajemen Pengendalian Gulma Kelapa Sawit (Elaeis guineensis Jacq.) di Bangun Koling Estate, PT Windu Nabatindo Abadi, Kotawaringin Timur, Kalimantan Tengah. [Skripsi]. Departemen Agronomi dan Hortikultura. Institut Pertanian Bogor. Bogor.

Prawirosukarto, S., Syamsuddin, E., Darmosarkoro ,W., Purba, A. 2005. Tanaman Penutup Tanah dan Gulma pada Kebun Kelapa Sawit. PPKS. Medan.

Rambe, T.D., Lasiman, P., Sudharto, P.S., Caliman, J.P. 2010. Pengelolaan Gulma pada Perkebunan Kelapa Sawit di PT. Smart Tbk. PT Smart Tbk, Jakarta.

Santosa, E., Zaman, S., Puspitasari, I.D. 2009. Simpanan biji gulma dalam tanah di perkebunan teh pada berbagai tahun pangkas. J Agron Indonesia. 37(1):46-54.

Sastroutomo, S.S. 1990. Ekologi Gulma. PT Gramedia Pustaka Utama. Jakarta.

Tjitrosoedirdjo, S.I., Utomo, Wiroatmojo, J., (Eds). 1984. Pengelolaan Gulma di Perkebunan. PT Gramedia. Jakarta. 210 hal.

Wijaya, E., Nusyirwan. 2013. Pengendalian Gulma Dengan Herbisida Glifosat Dan Metil 
Metsolfuron Pada Tanaman Kelapa Sawait Menghasilkan Di Perkebunan PT Melania Indonesia Kecamatan Banyuasin Sumatera Selatan. Universitas Sriwijaya, Palembang.

Yanto, R.R. 2017. Pengendalian laju pertumbuhan pucuk tanaman penutup tanah mucuna bracteata dc. Secara kimiawi. Skripsi. Departemen Agronomi dan Hortikultura. Institut Pertanian Bogor. Bogor.
Yulianto, Kesuma, N.W., Sinuraya, R. 2017. Efektivitas dan efisiensi knapsack sprayer dan knapsack motor pada penyemprotan gulma di perkebunan kelapa sawit. Jurnal Citra Widya Edukasi. 9 (1):80 - 92 